\title{
BIM 技术在隧道与地下工程中的应用研究
}

\author{
裴志明 \\ 中铁四局集团第二工程有限公司，江苏苏州 215131
}

\begin{abstract}
[摘要] 随着我国交通网络的不断发展, 人们逐渐开始选择高铁、动车作为出行交通工具, 因此隧道和地下管道也成为了重要 的交通设施。当前, 科技的不断发展, 使得 BIM 技术逐渐应用到隧道与地下工程的施工过程中, 对于提高隧道与地下工程的 施工质量和安全性起到了重要作用。基于此, 文中将针对隧道与地下工程的施工内容进行分析, 研究 BIM 技术在隧道与地下 工程中的实际应用，以期推动我国交通工程建设的不断发展。
\end{abstract}

[关键词]BIM 技术; 隧道与地下工程; 应用研究

DOI： 10.33142/aem.v2i6.2412 中图分类号: TU94;U455 文献标识码: A

\section{Research on Application of BIM Technology in Tunnel and Underground Engineering}

PEI Zhiming

The Second Engineering Co., Ltd. of CTCE Group, Suzhou, Jiangsu, 215131, China

\begin{abstract}
With the continuous development of China's transportation network, people gradually began to choose high-speed rail, bullet train as a means of transportation, so tunnels and underground pipelines have become important transportation facilities. At present, with the continuous development of science and technology, BIM Technology is gradually applied to the construction process of tunnel and underground engineering, which plays an important role in improving the construction quality and safety of tunnel and underground engineering. Based on this, this paper will analyze the construction content of tunnel and underground engineering, study the practical application of BIM Technology in tunnel and underground engineering, in order to promote the continuous development of China's traffic engineering construction.
\end{abstract}

Keywords: BIM technology; tunnel and underground engineering; application research

\section{引言}

隧道与地下工程的建设主要位于地下黑暗之中, 施工人员所面临的危险较多, 因此为了提高施工的安全性, 相关 管理人员应当注重采用现代化科技手段, 降低安全事故出现的概率, 及时排除安全隐患, 快速推进地下工程的建成 ${ }^{[1]}$ 。

1 隧道与地下工程建设的主要内容

1.1 隧道建设

地下隧道主要是为铁路铺设轨道提供场所而建, 其主要作用在于减少爬坡时间与距离、缩减运输路程 ${ }^{[2]}$ 。在隧道的 修建过程中, 相关工作人员首先应当确定隧道所在的具体位置, 根据位置及其周边环境情况来开展施工工作。在施工 过程中, 相关工作人员需要对隧道工作采取相应的保护措施, 避免隧道工程出现安全问题。具体而言, 在实际修建过 程中, 相关工作人员应当做好地下水测量和勘测工作, 了解隧道周边岩石的硬度及其种类, 判断隧道施工的正确的施 工方法，提高工程设计的合理性，为工程的顺利实施奠定基础。

1.2 地下工程

修建地下工程, 主要是为了节约地上资源, 充分利用地下闲置空间 ${ }^{[3]}$ 。开挖地下工程主要作用在于推进地下铁道建 设、水下隧道修筑以及地下公共街道修筑。除此之外, 地下工程的施工过程中还应当关注隧道工作的施工基础, 确保 双方合理开发与利用，保障双方工作能够相互促进，共同发展。

\section{BIM 技术的概念与作用}

BIM 技术是利用信息技术建筑模型建造设计管理与建造三维一体化数据系统的工具, 它能采用建立三维立体模型的 方式, 对设计图纸和方案进行具象化改进, 促进设计与施工相融合, 加强施工人员对于设计图纸的理解能力, 完善施 工的各项具体细节 ${ }^{[4]}$ 。同时, 科学合理的模型能够有效提高施工的效率, 便于相关施工人员快速查阅施工细节。BIM 技 术具有降低施工成本、节约制作开销的重要作用, 能够帮助设计人员简化设计图纸, 将复杂的设计数据变成简单的图 案，便于施工人员掌握设计意图，提高了施工的协调性和融合性，促进施工技术的发展。

3 BIM 技术用于隧道与地下工程的意义

3. 1 加速工程推进

BIM 技术用于隧道与地下工程, 能够有效提高设计部门与施工部门的交流, 使得制作与施工中遇到问题时能够直接 
按照图纸及时进行修改, 提高工程的实施速度, 确保工程能够按照原定的施工计划完成 ${ }^{[5]}$ 。就具体技术应用而言, 3D 模型与工程设计的有效结合, 使得隧道的建成与地下工程的开采勘测工作共同开展, 融为一体, 互相制约, 推进施工 工程的顺利完工。

\section{2 保障工程实施安全}

提高隧道与地下工程施工的安全性是 BIM 技术的最大优势, BIM 技术不仅能够及时处理问题, 还能完成一定的勘测 任务, 使得设计图纸更加直观立体, 帮助施工人员全面了解施工场地的具体情况, 尽可能减少模型与实际场地之间的 区别, 对于推导工作内容具有十分重要的意义, 确保施工的安全性保障具有实际意义, 提高工程整体的安全性, 确保 施工人员的人身安全。

\section{3 提升工程整体成果品质}

设计图纸得到立体优化后, 对于施工的整体效果将起到良好的提升作用, 同时, 借助现代化大数据技术的运算, 设计人员能够更好地还原工程的整体工作状态，推断工作效果，做好查漏补缺工作，尽可能地避免质量问题、相映问 题的产生，同时也能够直接提升工程的施工成果 ${ }^{[6]}$ 。

\section{4 隧道与地下工程中 BIM 技术的应用}

\section{1 工程技术平台的构建}

BIM 软件类型的不断增加, 使得隧道与地下工程技术平台的功能逐渐丰富。基于 BIM 模型创建性的软件, 相关人员 能够完成 3D 建模工作，基于 BIM 模型利用的软件，相关人员能够做好数据计算、仿真模拟等工作。在实际的施工过程 中, 对于 BIM 技术的具体应用而言, 工程管理人员应当积极构建工程技术平台, 结合各种 BIM 协同软件, 提高模型和 数据的准确性、完整性, 选择兼容性较好的相关软件。

\section{2 BIM 在隧道设计工作中的应用}

（1）优化模型架构工作

就具体的隧道设计工作而言, BIM 技术能够基于模型架构功能, 对于隧道的洞身、洞门进行设计 ${ }^{[7]}$ 。根据施工分部 展开合理的划分, 洞身主要可以分为超前支护还有初期支护以及二次祄砌与沟槽, 涉及到三十多个结构模型。设计人 员需要分类进行模型设计, 提高设计的层次感, 帮助施工人员明确结构设计的具体思路, 并做好后期检查和查询工作。 同时, 采用有效的命名方法对模型特征树进行命名, 充分利用 BIM 技术制作隧道结构树, 设置合理的底层数据口配置, 保存好有关设计模型的相关信息，为日后的查询做好准备。

(2) 促进实时驱动修改

对于隧道断面来讲, 其断面大多数是规范规定的标准断面, 参数化设计能够满足各种类型的断面模型的可视化修 改也可以称之为实时驱动修改。就具体的施工控制工作而言, 模型驱动能够确保控制参数的精准性, 确保控制参数能 够与 BIM 软件有效链接起来。BIM 技术软件通常包括开放的数据, 这些数据在经过二次开发后, 能够为隧道施工模型提 供附加信息。

(3) 开展碰撞检查工作

隧道施工本身具有一定危险性, 因此对于施工的安全性和稳定性要求较高, 针对施工中可能受到的各种干扰, 应 当采用科学的检测方面, 提高安全施工水平。BIM 技术的可视化三维模型能够开展碰撞检查。碰撞检查的内容主要涉及 到铁路隧道内结构上的碰撞还有管线与隧道结构的碰撞还有管线与管线之间的碰撞等方面。设计人员在设计过程中应 当首先利用 BIM 软件展开相关检查, 并在实施过程中做好动态地、及时地调整, 从而有效减少施工过程中进行设计方 面的大变更。为了提高施工的安全性, 工程管理人员还应当注意在消防方面以及紧急疏散还有通风等方面的工作, 对 于该方面的分析同样可以借助 BIM 模型进行分析。

\section{5 结语}

综上所述, BIM 技术应用于隧道与地下工程的施工中, 已成为新的发展趋势, 不仅具有提高施工设计水平和提升隧 道建设安全性的重要作用, 还具有先进性、智能性、准确性的优势, 对于推动我国建筑工程整体实现智能化具有重要 意义。在结合 BIM 技术进行隧道与地下工程的施工过程中, 相关施工人员应当不断提高 BIM 技术应用水平, 认真研究 相关技术，保障具体施工工程的安全性和稳定性。

\section{[参考文献]}

[1]夏诗画,施彦. 基于 BIM 的山地城市隧道工程三维设计及应用研究 [J]. 公路交通技术, 2019,35(06): 73-80.

[2] 汪勇, 付豪, 李响,季錭宇. BIM 技术在山地城市大型市政工程中的应用一一新燕尾山隧道工程 BIM 应用 [J]. 城市道桥 与防洪, $2020(06): 248-251$.

[3]王浩. 基于达索平台的隧道BIM 模型骨架线二次开发与信息附加 [J]. 铁路计算机应用, 2020, 29(04): 23-27.

[4] 李晓军, 田吟雪, 陈树汪, 王安民。建筑信息模型 (BIM) 技术在隧道工程中应用现状与分析 [J]. 隧道建设 (中英 文) , 2020,40 (07) : 953-963.

作者简介: 裴志明（1982.6.12-), 男, 籍贯: 河北唐山, 单位: 中铁四局集团第二工程有限公司, 学历: 本科, 研究 方向：地下工程与隧道。 